\title{
Predicting Malignancy in a Solitary Thyroid Nodule: A Prospective Study on the Role of Color Doppler Ultrasonography
}

\author{
${ }^{1}$ Gururaja Rao, ${ }^{2}$ Shilpa Rao, ${ }^{3}$ Ravi Varma, ${ }^{4}$ Nikhil M Bhagwat, ${ }^{5}$ Manoj D Chadha \\ ${ }^{6}$ Ameya S Joshi, ${ }^{7}$ Premlata K Varthakavi
}

\begin{abstract}
Palpable thyroid nodules are fairly common. While many are benign, the clinician faces the challenge of detecting the 4 to $14 \%$ of malignant lesions. Fine needle aspiration cytology (FNAC) of thyroid nodules seems to have eclipsed all other techniques for diagnosis of thyroid cancer, but has its limitations when a nodule is inaccessible or in the case of follicular neoplasm. This study from a hospital from Indian west coast shows that vascular flow pattern of extensive peripheral and central flow (Type-3) or a central flow only (Type-4) and a resistive index (RI) of $>0.75$ on power Doppler sonography shows a healthy sensitivity and excellent specificity for predicting malignancy. The utility becomes even more apparent among follicular neoplasms where FNAC can offer little help in distinguishing malignancy.
\end{abstract}

Keywords: Ultrasonography, Thyroid nodules, Thyroid neoplasms, Fine-needle aspiration, Color Doppler, Resistive index, Carcinoma, Papillary, Follicular, Thyroid.

How to cite this article: Rao G, Rao S, Varma R, Bhagwat NM, Chadha MD, Joshi AS, Varthakavi PK. Predicting Malignancy in a Solitary Thyroid Nodule: A Prospective Study on the Role of Color Doppler Ultrasonography. Int J Otorhinolaryngol Clin 2014;6(1):9-14.

\section{Source of support: Nil}

Conflict of interest: None

\section{INTRODUCTION}

Palpable thyroid nodules occur in 4 to $7 \%$ of the general adult population, but nodules found incidentally on ultrasonography ${ }^{1-3}$ suggest a prevalence of 19 to $27 \%$. Although,

\footnotetext{
${ }^{1,5}$ Associate Professor, ${ }^{2}$ Professor and Unit Chief

${ }^{3,6}$ Assistant Professor, ${ }^{4}$ Additional Professor

${ }^{7}$ Professor and Head

${ }^{1}$ Department of Medicine, Yenepoya Medical College, Mangalore Karnataka, India

${ }^{2}$ Department of General Surgery, GSMC and KEM Hospital Mumbai, Maharashtra, India

${ }^{3}$ Department of Radiology, BYL Nair Hospital and Topiwala National Medical College, Mumbai, Maharashtra, India

${ }^{4-7}$ Department of Endocrinology, BYL Nair Hospital and Topiwala National Medical College, Mumbai, Maharashtra, India
}

Corresponding Author: Nikhil M Bhagwat, Additional Professor Department of Endocrinology, BYL Nair Hospital and Topiwala National Medical College, Mumbai, Maharashtra, India, Phone: 9820238399, e-mail: bhagwatnik@yahoo.co.in most thyroid nodules are benign, approximately 4 to $14 \%$ are malignant. ${ }^{4}$ In an era, when patients are advised on methods of self-examination to detect cancer at an early stage, the finding of a not palpable abnormality in such a superficial location as the thyroid gland can be disconcerting.

Several clinical features, radiological findings on ultrasonography ${ }^{5}$ and Doppler ${ }^{6}$ and fine needle aspiration cytology ${ }^{7}$ may help sifting malignant nodules from the vast majority which are benign.

Fine needle aspiration cytology (FNAC) of thyroid nodules seems to have eclipsed all other techniques for diagnosis of thyroid cancer, with reported overall rates of sensitivity and specificity exceeding $90 \%$ in iodine sufficient areas. ${ }^{8-11}$ However, it has shortcomings. It is an invasive procedure; it is not applicable to all nodules (e.g. small nodules, in inaccessible nodules) and it provides no information about any other nodules that the patient may have.

Fine needle aspiration cytology presents a particular challenge in the case of a follicular neoplasm. Cytopathology cannot confirm whether the lesion is benign or malignant. Repeating the biopsy (or FNAC) rarely clarifies the nature of the nodule. However, considering up to $80 \%$ probability that the nodule is benign points to the need for exploring an alternative diagnostic modality to help in decision making.

The fusion of color flow imaging with Doppler technology has made it possible to study the hemodynamics of thyroid nodules. The premise was that the vascular pattern displayed on color flow imaging and Doppler indices obtained by interrogating the vessels in neoplastic nodules should reflect their abnormal vascularity. This can be used to differentiate neoplastic from other nodules and possibly benign from malignant neoplasms.

Several small studies and case series have demonstrated that a pattern of either spotty intranodular flow ${ }^{12}$ or hypervascular central flow ${ }^{6,13,14}$ on color Doppler sonography ${ }^{15}$ may be associated with malignancy. This finding holds great promise as it means that it may be possible to devise a noninvasive technique for detecting thyroid malignancies with accuracy comparable to tissue sampling. Such an innovation will be a great boon to health services in our country, considering the prevalence of thyroid incidentalomas in our country. 
Hence, we decided to conduct a prospective study to evaluate the benefit of color Doppler sonography in thyroid nodules.

\section{AIMS AND OBJECTIVES}

The current study was designed on solitary thyroid nodules to:

- Study the vascular flow pattern and color Doppler findings in benign $v s$ malignant nodular thyroid lesions.

- To correlate these findings with cytopathology and surgical histology.

- To determine if Doppler findings (vascular flow patterns and resistive index) help in discriminating benign from malignant among follicular neoplasms.

\section{MATERIALS AND METHODS}

This prospective study was carried out in the thyroid clinic, of a tertiary care teaching institute in Mumbai, a coastal city in western India.

The study protocol was approved by the Institutional Ethics Committee. Informed consent was obtained from the patient or parent/guardian as applicable.

\section{Inclusion Criteria}

Patients who presented clinically with a solitary thyroid nodule.

\section{Exclusion Criteria}

- Multinodular goiters

- Autonomously functioning thyroid nodules

- Patients with thyrotoxicosis.

Detailed history was obtained, physical examination was done in all the patients.

Thyroid function tests were done in all the patients by chemiluminescent immunoassay (CLIA) method.

\section{Ultrasonography and Color Doppler}

All the patients underwent ultrasonography and Doppler prior to FNAC. Technetium $99 \mathrm{~m}$ scan was done whenever feasible after injection of $5 \mathrm{mCi}$ of $99 \mathrm{~m}$ pertechnetate.

The equipment used for ultrasonography and color Doppler was Siemens G 50 with linear probe (5 to $10 \mathrm{MHz}$ frequency). The maximum used frequency was $7.5 \mathrm{MHz}$ both for color and color Doppler. All studies were done by the same radiologist on the same machine making the necessary adjustments to pulse repetition, frequency, wall filter and sample volume size to optimize slow flow imaging and to minimize artifacts. All patients were asked to hold breath during the relevant duration of the examination and while capturing images.

The size of the thyroid gland and nodule size were examined on ultrasonography. The echogenicity of the nodule was noted.

For solitary thyroid nodule, two parameters were evaluated on thyroid Doppler:

1. Resistive index (RI)

2. Vascular flow pattern.

The RI was calculated using Doppler in all patients with visible flow as below: ${ }^{16}$

$$
\mathrm{RI}=\frac{\mathrm{S}-\mathrm{D}}{\mathrm{S}}
$$

$\mathrm{S}=$ Height of systolic peak

$\mathrm{D}=$ Height of end diastolic peak

The vascular flow pattern was classified into five types as shown in Figure 1: $:^{16}$

- Type 0: No visible flow

- Type 1: Peripheral flow only

- Type 2: Peripheral flow with small amount of central flow

- Type 3: Peripheral with extensive central flow

- Type 4: Central flow only.

\section{Fine Needle Aspiration Cytology}

All the patients underwent FNAC using a 25 gauge needle and a disposable $2 \mathrm{cc}$ syringe for obtaining thyroid samples. Drawing $1 \mathrm{cc}$ of air into the syringe prior to the aspiration was done to facilitate expelling cytology specimen after the procedure. The slides were fixed immediately by placing in alcohol and stained with Papanicolaou and Giemsa stains.

Any aspiration that contained neither colloid nor epithelial cells as per guidelines of the Papanicolaou Society was considered inadequate ${ }^{17}$ and was repeated using ultrasonographic guidance.

\section{Histopathological Examination}

Histopathological examination of the thyroid gland was performed in those patients who underwent surgery. The Doppler findings were corroborated with FNAC and surgical histopathology in operated cases.

\section{RESULTS}

We analyzed the findings in 80 patients who presented to us clinically and were confirmed to have solitary thyroid nodule (STN). 

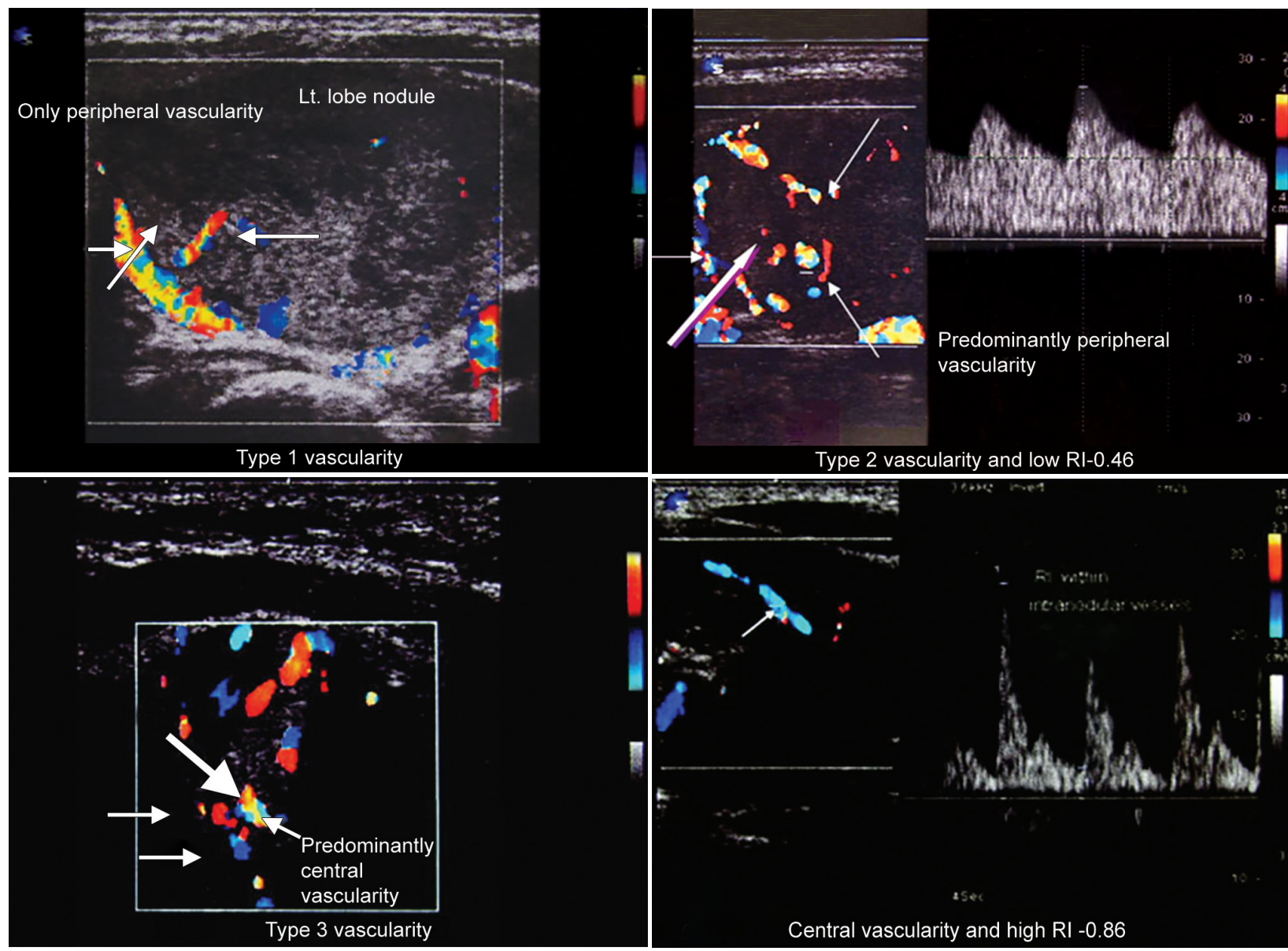

Fig. 1: Thyroid Doppler-vascular flow patterns

\section{Age}

The age of the patients ranged from 14 to 66 years (mean age $=34.7$ years). Thirty-four percent patients were in the 26 to 35 years range. Mean duration of the swelling at presentation was 21.76 months.

\section{FNAC Diagnosis (Non-neoplastic vs Neoplastic)}

On FNAC 50 (62\%) nodules were benign (nonneoplastic) and $8(27 \%)$ were malignant (4 papillary carcinomas, 3 medullary carcinomas, and 1 Hürthle cell lesion) (Fig. 2).

Twenty-two $(28 \%)$ were diagnosed to have follicular neoplasms (Fig. 2).

\section{Doppler Features}

\section{Resistive Index (Fig. 3)}

An RI cutoff of 0.75 has been shown to have good tradeoff between high specificity and sensitivity in literature. ${ }^{16}$

In our study as well, RI of 0.75 showed a healthy sensitivity and excellent specificity for predicting malignancy (Fig. 4).

Overall RI of 0.75 shows a healthy sensitivity and excellent specificity for predicting malignancy.

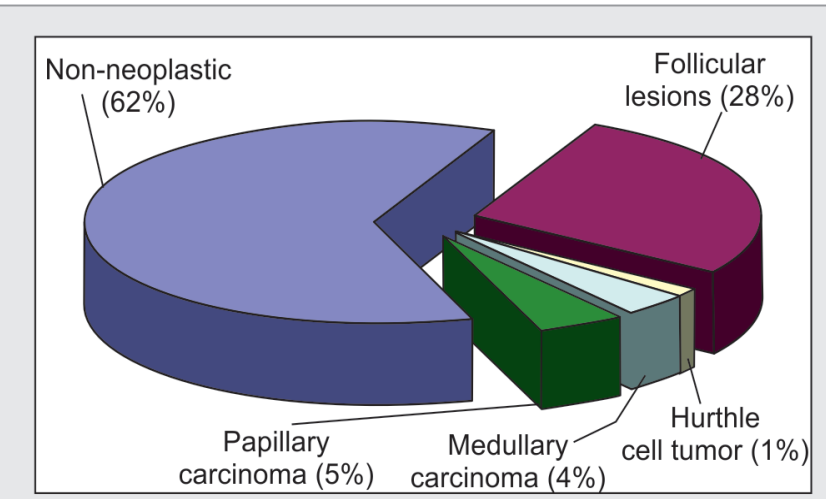

$\square$ Non-neoplastic $\quad \square$ Follicular lesions $\square$ Hurthle cell tumor $\square$ Medullary carcinoma $\square$ Papillary carcinoma

Fig. 2: Distribution of lesion types on FNAC (non-neoplastic vs neoplastic)

\section{Flow Patterns (Fig. 4)}

Benign thyroid nodules revealed type 0 to 3 flow pattern.

Type 3 and 4 vascularity was predominantly seen in malignant nodules.

Only one ( $7.69 \%$ ) benign nodule (follicular adenoma) had a type 4 vascular pattern. This patient has Hashimoto's thyroiditis which could possibly explain the altered vascularity. 


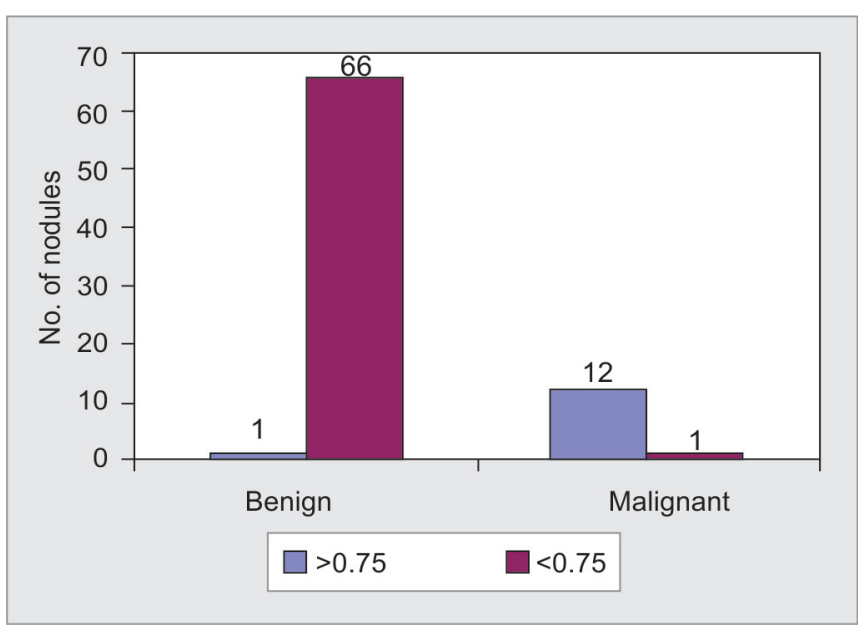

Fig. 3: Resistive index of benign and malignant nodules $[p<0.0001$ (Fisher's exact test): Sensitivity $=0.92$; Specificity $=0.99$; Positive predictive value $=0.92$; Negative predictive value $=0.99$ ]

\section{Application}

Benign on FNAC and malignant on histopathology: One of the patients who had benign lesion on FNAC had
Doppler features suggestive of malignancy $(\mathrm{RI}=0.76$ and type 3 vascularity). Histopathology confirmed malignancy (follicular carcinoma) in this patient.

Papillary carcinoma was diagnosed on FNAC in four patients. Three showed Doppler features of malignancy which was confirmed on histopathology (Fig. 5). The remaining nodule did not show any vascularity on Doppler studies (benign feature) and the nodule was confirmed benign on histopathology after surgery.

Among patients with papillary lesions on FNAC all the lesions with RI $>0.75$ had type 3 to 4 vascularity and those with $\mathrm{RI}<0.75$ had type 1 to 2 vascularity.

Histopathology confirmed the FNAC diagnosis of medullary carcinoma (Fig. 6) in all the three cases of medullary thyroid carcinoma. However, Doppler features suggestive of malignancy was seen in two cases. That we should be aware of the limitations of Doppler is brought out by the one case negative on Doppler. That patient had absent isthmus.

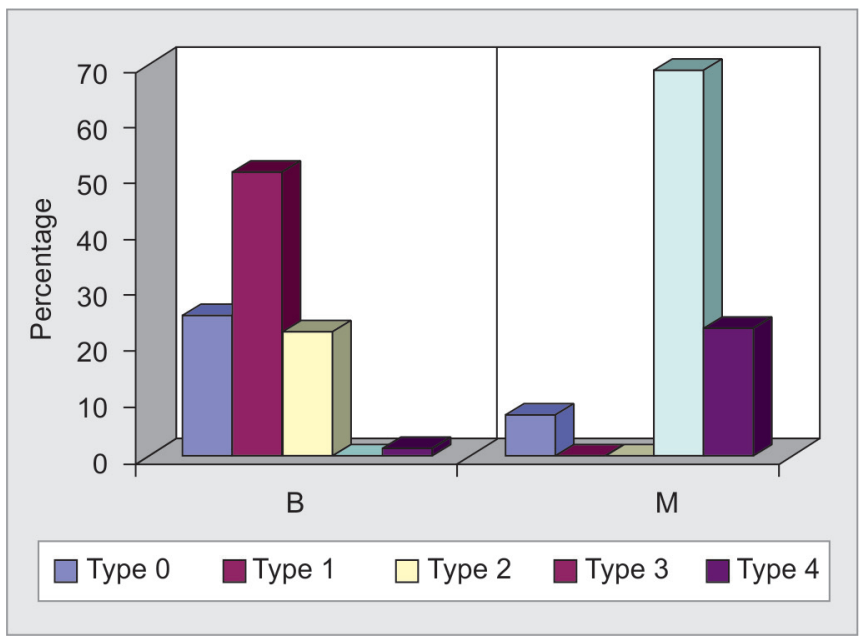

\begin{tabular}{|c|c|c|}
\multicolumn{2}{|c|}{$p<0.0001$ (Fisher's exact test) } \\
\hline & Benign (\%) & Malignant (\%) \\
\hline Type 0 & 25.37 & $7.69^{*}$ \\
Type 1 & 50.75 & 0 \\
Type 2 & 22.39 & 0 \\
\cline { 2 - 3 } Type 3 & 0 & 69.23 \\
Type 4 & 1.49 & 23.08 \\
\hline
\end{tabular}

Fig. 4: Flow patterns in benign vs malignant nodules

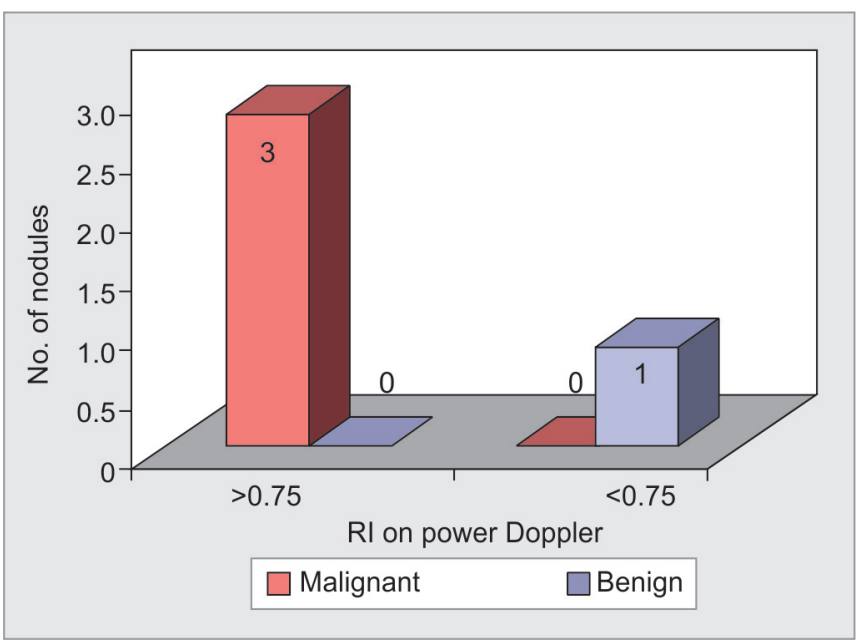

Fig. 5: Assessment of ability of RI in discriminating benign from malignant among patients diagnosed as papillary carcinoma on FNAC $(p<0.0001$ : Sensitivity $=100 \%$; Specificity $=100 \%$; Positive predictive value $=100 \%$; Negative predictive value $=100 \%$ )

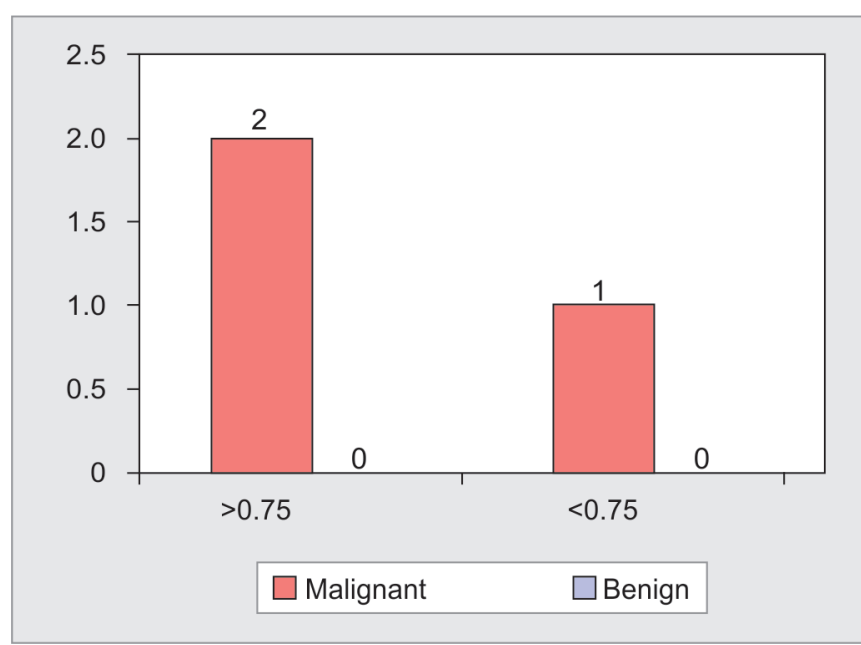

Fig. 6: Assessment of ability of $\mathrm{Rl}$ in discriminating benign from malignant among patients diagnosed as medullary carcinoma on FNAC 


\section{Follicular Neoplasms on FNAC}

This chart (Fig. 7) demonstrates how FNAC did not reliably differentiate benign from malignant among follicular neoplasms. Among 22 patients diagnosed as having follicular neoplasm on FNAC, 15 underwent surgery and their histopathology report was available. Of these 15 neoplasms, seven $(46.7 \%)$ were diagnosed as follicular adenoma; four $(26.7 \%)$ as follicular carcinoma; one $(6.7 \%)$ papillary carcinoma and three (20\%) as non-neoplastic lesions.

Among patients with follicular lesions on FNAC all the lesions with RI $>0.75$ had type 3 to 4 vascularity and those with $\mathrm{RI}<0.75$ had type 1 to 2 vascularity.

Six of the 22 FNAC diagnosed follicular neoplasms had Doppler features of malignancy (Fig. 8). Among them five were proven malignant on histopathology (follicular carcinoma -4; papillary carcinoma-1) (specificity $=94 \%)($ Fig. 8).

Remaining one patient who had Doppler features of malignancy was shown to have follicular adenoma and Hashimoto's thyroiditis on histopathology which could possibly explain the altered vascularity.

All 16 follicular neoplasms diagnosed on FNAC which did not have Doppler features of malignancy (neither flow pattern nor resistive index), were proven benign on histopathology (Follicular adenoma-12 and non-neoplastic - 4) - (negative predictive value $=100 \%$ ).

Hence, preoperative color Doppler gives the surgeon a guidance as to which lesions should undergo more than a hemithyroidectomy thereby avoiding complications of unindicated extensive surgery.

\section{Other Limitations of Color Doppler}

- False positivity in the presence of thyroiditis, like the case with one of our patients with Hashimoto's thyroiditis.

- Autonomously functioning thyroid nodules (excluded in our study).

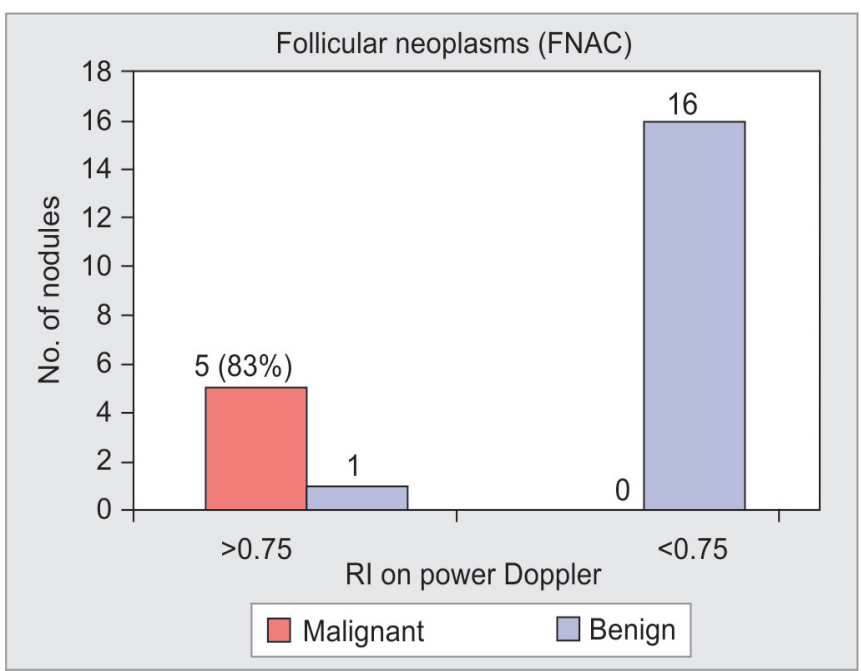

Fig. 8: Assessment of ability of RI in discriminating benign from malignant among patients diagnosed as follicular lesions on FNAC (Sensitivity $=100 \%$; Specificity $=94 \%$; Positive predictive value $=$ $83 \%$; Negative predictive value $=100 \%$ )

\section{DISCUSSION}

Fine needle aspiration cytology can be as good as you make it, and vice versa. ${ }^{11}$ When FNAC provides inadequate numbers of benign-appearing cells to exclude malignancy, and there are no clinical features to suggest malignancy, the dilemma about watchful observation begins. Another test with similar robustness can come to our rescue in such a scenario.

A study by Frates et al showed that among solid nodules, the prevalence of malignancy was greater (nearly three times) when the nodule was hypervascular ${ }^{18}$ than when the flow pattern was less than four.

Among our patients with papillary lesions virtually all the patients with papillary thyroid carcinoma showed RI $>0.75$ and had type 3 to 4 vascularity and no benign lesion had this kind of vascularity (Fig. 5). Thus, our study

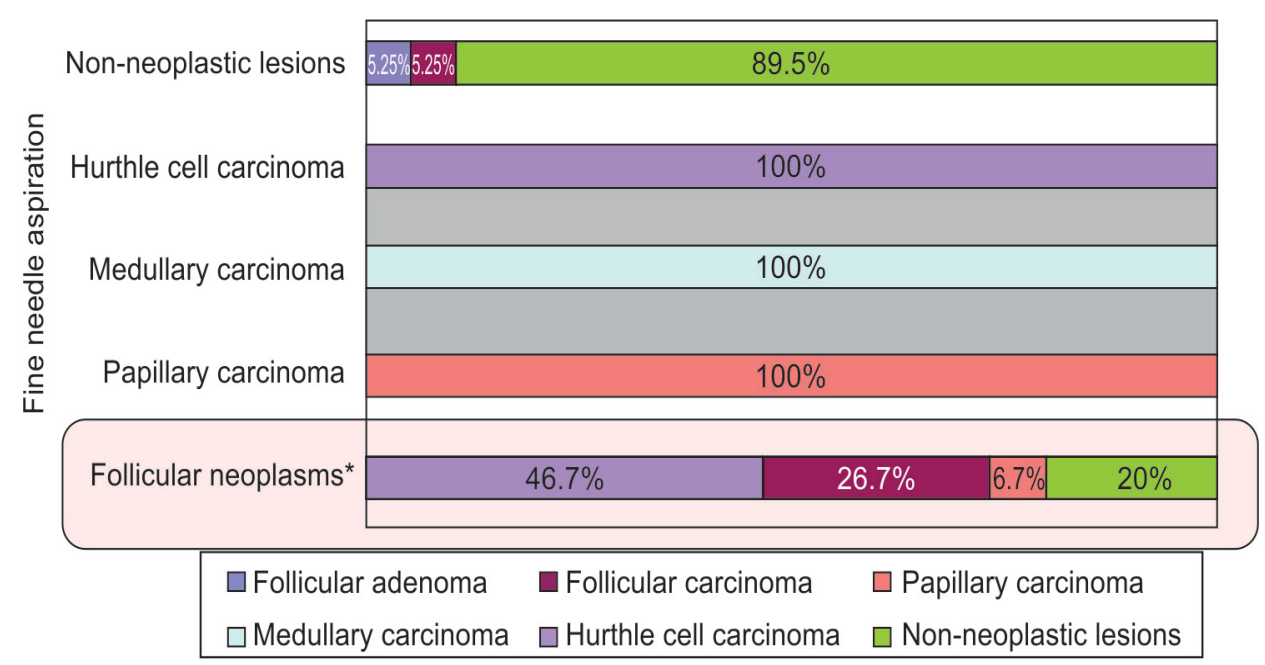

Fig. 7: Association between FNAC and histopathology report in patients with various neoplasms as diagnosed on FNAC (Sensitivity $=100 \%$; Specificity $=94 \%$; Positive predictive value $=83 \%$; Negative predictive value $=100 \%$ ) 
shows that it can be a useful adjunct to FNAC which though accurate is invasive.

Follicular lesions on FNAC can present a particular challenge as this modality is weak in differentiating benign from malignant lesions. Vascular flow pattern and color Doppler can aid us in this scenario.

As per the study by De Nicola et al an RI cutoff of 0.75 had good accuracy, specificity, and negative predictive value but had low sensitivity and positive predictive value (respectively, 91, 97, 92, 40 and 67\%) for thyroid follicular neoplasms. ${ }^{16}$

Using a RI cutoff of 0.75 , we observed a specificity of $94 \%$ and negative predictive value of $100 \%$ making Doppler really worthwhile in distinguishing benign from malignant follicular lesions (Fig. 8).

Among both papillary and follicular lesions RI pattern suggestive of malignancy $(>0.75)$ was always associated with vascularity type suggestive of malignancy on Doppler. So, both seem to complement each other.

Overall a healthy sensitivity coupled with robust negative predictive value $(\mathrm{NPV}=99 \%)$ boosts confidence in this being a promising tool in clinical decision making.

\section{CONCLUSION}

Color Doppler is a noninvasive investigation which can differentiate between and malignant solitary thyroid nodules. Resistive index of $>0.75$ and type 3 or greater flow pattern on Doppler reliably predicts malignancy. It can be especially helpful in characterizing follicular neoplasms.

It could play a pivotal role in supplementing FNAC in the algorithm for the evaluation of solitary thyroid nodules, considering its accuracy, cost-effectiveness, easy availability and noninvasive nature. This can help not only in avoiding unnecessary surgery but also facilitate necessary surgery by helping the surgeon to be prepared and plan in advance for a malignant neoplasm.

\section{REFERENCES}

1. Carroll BA. Asymptomatic thyroid nodules: incidental sonographic detection. Am J Roentgenol 1982;138(3):499-501.

2. Woestyn J, Afschrift M, Schelstraete K, Vermeulen A. Demonstration of nodules in the normal thyroid by echography. Br J Radiol 1985;58(696):1179-1182.

3. Brander AE, Viikinkoski VP, Nickels JI, Kivisaari LM. Importance of thyroid abnormalities detected at US screening: a 5-year follow-up. Radiology 2000;215(3):801-806.

4. Mazzaferri EL. Management of a solitary thyroid nodule. New England J Med 1993;328(8):553-559.
5. Marqusee E, Benson CB, Frates MC, Doubilet PM, Larsen PR, Cibas ES, et al. Usefulness of ultrasonography in the management of nodular thyroid disease. Annals of Internal Medicine 2000;133(9):696-700.

6. Pacella CM, Guglielmi R, Fabbrini R, Bianchini A, Rinaldi $\mathrm{R}$, Panunzi C, et al. Papillary carcinoma in small hypoechoic thyroid nodules: predictive value of echo color doppler evaluation. Preliminary results. J Exp Clinic Cancer Res: CR 1998; 17(1):127-128.

7. Cochand-Priollet B, Guillausseau PJ, Chagnon S, Hoang C, Guillausseau-Scholer C, Chanson P, et al. The diagnostic value of fine needle aspiration biopsy under ultrasonography in nonfunctional thyroid nodules: a prospective study comparing cytologic and histologic findings. Am J Med 1994;97(2):152-157.

8. Cooper DS, Doherty GM, Haugen BR, Kloos RT, Lee SL, Mandel SJ, et al. Revised American Thyroid Association management guidelines for patients with thyroid nodules and differentiated thyroid cancer. Thyroid: Official J Am Thyr Assoc 2009;19(11):1167-1214.

9. Hegedus L, Bonnema SJ, Bennedbaek FN. Management of simple nodular goiter: current status and future perspectives. Endocrine Reviews 2003;24(1):102-132.

10. Papini E, Guglielmi R, Bianchini A, Crescenzi A, Taccogna S, Nardi F, et al. Risk of malignancy in nonpalpable thyroid nodules: predictive value of ultrasound and color Doppler features. J Clin Endocrinol Metabol 2002;87(5):1941-1946.

11. Hamburger JI. Diagnosis of thyroid nodules by fine needle biopsy: use and abuse. J Clin Endocrinol Metabol 1994; 79(2):335-339.

12. Shimamoto K, Endo T, Ishigaki T, Sakuma S, Makino N. Thyroid nodules: evaluation with color Doppler ultrasonography. Journal of ultrasound in medicine: Official J Am Institute of Ultrasound in Med 1993;12(11):673-678.

13. Kerr L. High-resolution thyroid ultrasound: the value of color Doppler. Ultrasound Q 1994;12:21-43.

14. Clark KJ, Cronan JJ, Scola FH. Color Doppler sonography: anatomic and physiologic assessment of the thyroid. J Clin Ultrasound: 1995;23(4):215-223.

15. Cerbone G, Spiezia S, Colao A, Di Sarno A, Assanti AP, Lucci $\mathrm{R}$, et al. Power Doppler improves the diagnostic accuracy of color Doppler ultrasonography in cold thyroid nodules: followup results. Hormone Research 1999;52(1):19-24.

16. De Nicola H, Szejnfeld J, Logullo AF, Wolosker AM, Souza LR, Chiferi V Jr. Flow pattern and vascular resistive index as predictors of malignancy risk in thyroid follicular neoplasms. Journal of ultrasound in medicine: Official J Am Institute Ultrasound Med 2005;24(7):897-904.

17. Guidelines of the Papanicolaou Society of Cytopathology for the examination of fine-needle aspiration specimens from thyroid nodules. The Papanicolaou Society of Cytopathology Task Force on Standards of Practice. Diagnostic Cytopathology 1996;15(1):84-89.

18. Frates MC, Benson CB, Doubilet PM, Cibas ES, Marqusee E. Can color Doppler sonography aid in the prediction of malignancy of thyroid nodules? Journal of ultrasound in medicine: Official J Am Institute Ultrasound Med 2003;22(2):127-131. 